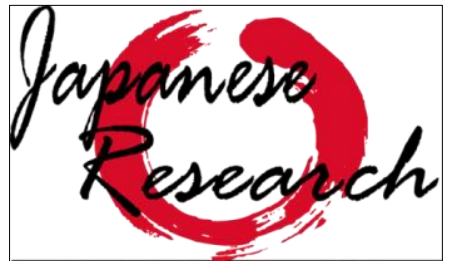

on Linguistics, Literature and Culture
Japanese Research on Linguistics, Literature, and Culture Vol. 2 No. 1 Nov. 2019, p., 77-92 ISSN Online: 2655-4836

DOI: $10.33633 /$ jr.vlil.3443

http://publikasi.dinus.ac.id/index.php/jrllc/article/view/3443/1855 japanese.research@fib.dinus.ac.id

Published by Universitas Dian Nuswantoro, Semarang

\title{
Pronomina Persona Omae pada Komik One Piece Volume 17 Karya Eichiro Oda
}

\author{
Sharnetta Florenzia Godjali \\ Universitas Dian Nuswantoro \\ 3122010000293@mhs.dinus.ac.id
}

Article History: Submitted date 2019-10-28; Accepted date 2019-11-3; Published date 2019-11-30

\begin{abstract}
This research disccusses about the use of personal pronoun omae on comic One Piece Volume 17. The purpose of this research is to analyse how using second person pronoun omae. In the concept uchi-soto which applied by the speakers for the interlocutors. The data of this research were analyzed by using uchi-soto concept proposed by Nakane Chie and Hirabayashi-Hama. It also discusses the factors of using polite language. The result of the data analysis show that omae is used in formal and informal context. It also used by the speakers to speak with various kind of interlocutors : close friends, outsiders, or enemies. It also used by both female and male.
\end{abstract}

Keywords : second person pronouns, uchi-soto, omae, speaker, listener

\begin{abstract}
Abstrak
Penelitian ini membahas penggunaan pronomina persona omae pada komik One Piece Volume 17. Tujuan penelitian ini adalah menganalisa bagaimana pemakaian kata ganti kedua omae. Di dalam konsep uchi-soto yang diterapkan oleh penutur kepada lawan bicara. Data dalam penelitian ini dianalisis menggunakan konsep uchisoto menurut Nakane Chie dan Hirabayashi-Hama serta faktor-faktor penggunaan bahasa santun. Dari hasil analisis data dapat disimpulkan bahwa pemakaian omae digunakan saat situasi formal dan informal, juga digunakan kepada penutur untuk berbicara dengan mitra tutur, baik yang dekat dengan penutur maupun orang yang tidak dikenal dan musuh penutur. Pemakaian omae tidak hanya digunakan oleh lakilaki, bisa digunakan oleh perempuan pada dialog tersebut.
\end{abstract}


Kata kunci : persona pronomina kedua, uchi-soto, omae, penutur, mitra tutur

\section{Pendahuluan}

Bahasa adalah salah satu hasil dari kebudayaan manusia yang tinggi nilainya karena dengan bahasa manusia dapat berinteraksi dan berkomunikasi dengan individu di sekitarnya. Komunikasi dan interaksi dapat berjalan dengan lancar apabila bahasa tersebut digunakan sesuai dengan situasi dan kondisi pembicaraan. Dalam komunikasi itulah,kita sering menggunakan kata ganti yakni disebut persona pronomina untuk memanggil lawan bicara kita yang sudah kenal ataupun yang belum kita kenal, sehingga persona pronomina juga memiliki peranan penting dalam komunikasi antara manusia satu dengan lainnya. Dalam bahasa Jepang, disebut ninshoo daimeishi, memiliki fungsi dan penggunaan tergantung dari jenis kelamin, usia, status sosial, hubungan antara pembicara dan lawan bicara seperti hubungan atasan bawahan, hubungan derajat keakraban yang semuanya turut mempengaruhi pemilihan ninshoo daimeishi. Pemakaian kata inilah yang ingin mengkaji di dalamnya, pemakaian kata dalam sapaan seseorang ke orang lain termasuk dalam pemakaian kata ganti orang yang disebut dengan pronomina persona. Pronomina persona,ada 3 macam yakni kata ganti orang pertama, kedua, dan ketiga.

Masyarakat Jepang membagi diri mereka melalui keanggotaan di dalam atau di luar grup, yang biasa dikenal dengan istilah uchi (内) dan soto (外). Uchi (内) dapat didefinisikan sebagai di dalam, rumah saya atau tanah air, kelompok tempat kita bergabung, dan istri atau suami. Sementara soto (外) berarti pihak luar, di luar, kelompok lain dan luar rumah (Davies, 2002: 217). Dalam komunikasi itu ada juga interaksi dalam pembagian orang dalam 1 kelompok yakni adanya konsep uchi-soto yang bisa kita kenal konsep dalam dan luar. Konsep uchi-soto merupakan merupakan salah satu sistem yang sangat mempengaruhi interaksi antar individu di Jepang. Konsep ini didasarkan pada pemikiran bahwa seseorang harus mengidentifikasikan dirinya sendiri dengan keluarganya maka ketika seseorang berbicara kepada orang lain (soto) mengenai keluarganya (uchi), ia membicarakan mereka dengan cara yang sama seperti ketika ia membicarakan dirinya sendiri. Tidak digunakan bentuk sopan saat membicarakan keluarganya 
karena akan terdengar aneh jika berbicara mengenai diri sendiri dengan bentuk sopan (sonkeigo).

Chaer (2004) berpendapat bahwa Sosiolinguistik merupakan perpaduan dari dua sub bidang keilmuan yakni sosiologi dan linguistik. Sosiologi adalah ilmu yang mempelajari masalah sosial yang ada di masyarakat sedangkan linguistik adalah bidang yang mempelajari bahasa atau mengambil bahasa sebagai objek kajiannya. Dapat disimpulkan bahwa Sosiolinguistik adalah bidang ilmu yang mempelajari ciri-ciri dan variasi bahasa serta mengkaji hubungan antarbahasa dengan masyarakat penutur.

Oleh karena itu, penulis tertarik untuk menganalisis tentang penggunaan persona pronomina atau kata ganti orang kedua dalam kata omae yang dilihat dalam konsep uchi-soto di komik One Piece volume 17, dengan alasan situasi komik shounen yakni komik yang ditujukan remaja pria dan penulis menemukan banyaknya penggunaan Omae serta faktor apa saja yang dapat mempengaruhi cara dia memanggil orang dalam awal berkomunikasi.

\subsection{Kajian Teoretis}

\section{Sosiolinguistik}

Sosiolinguistik merupakan cabang linguistik yang secara etimologi kata tersebut berasal dari bahasa Inggris, yaitu terdiri atas kata "socio" dan "linguistics". Linguistik yaitu ilmu yang mempelajari atau membicarakan bahasa, khususnya unsur-unsur bahasa (fonem, morfem, kata, kalimat) dan hubungan antara unsur-unsur itu termasuk hakikat dan pembentukan unsur-unsur itu. Unsur sosio adalah seakar dengan sosial, yaitu yang berhubungan dengan masyarakat, kelompok-kelompok masyarakat, dan fungsi kemasyarakatan. Jadi, sosiolinguistik adalah studi atau pembahasan dari bahasa sehubungan dengan penutur bahasa itu sebagai anggota masyarakat.

Carol dalam Sanada (1992: 9) mendefinisikan bahwa yang dimaksud dengan sosiolinguistik adalah

社会言語学とは、社会と中で生きる人間、乃至その集団とかかわりにおいて名言 語現象あるいは言語運用とらえようとする学問である。 Sosiolinguistik adalah ilmu yang membahas fenomena bahasa atau penggunaan bahasa yang berkaitan dengan kelompok atau manusia yang berada di dalam masyarakat. 
Dalam sosiolinguistik ada kemungkinan orang memulai dari masalah kemasyarakatan kemudian mengaitkan dengan bahasa, tetapi bisa juga berlaku sebaliknya mulai dari bahasa kemudian mengaitkan dengan gejala-gejala kemasyarakatan. Sosiolinguistik dapat mengacu pada pemakian data kebahasaan dan menganalisis kedalam ilmu-ilmu lain yang menyangkut kehidupan sosial, dan sebaliknya mengacu kepada data kemasyarakatan dan menganalisis ke dalam linguistik. Misalnya orang bisa melihat dulu adanya dua ragam bahasa yang berbeda dalam satu bahasa kemudian mengaitkan dengan gejala sosial seperti perbedaan jenis kelamin sehingga bisa disimpulkan, misalnya ragam (A) didukung oleh wanita, ragam (B) didukung oleh pria dalam masyarakat itu atau sebaliknya, orang bisa memulai dengan memilah masyarakat berdasarkan jenis kelamin menjadi pria- wanita, kemudian menganalisis bahasa atau tutur yang bisa dipakai wanita atau tutur yang bisa dipakai pria.

\section{Pronomina Persona (Ninshoo Daimeishi)}

Pronomina Persona adalah penggunaan kata ganti orang yang lebih dulu disebut kepada orang yang berbicara kepada kita dan juga kata yang menunjuk orang, sesuatu, tempat, dan sebagainya yang biasanya digunakan tanpa menyebut nama orang tersebut (Drohan,1992:30).

Kata ganti orang ada beberapa 3 jenis yaitu kata ganti orang pertama yang mengacu pada diri sendiri, kata ganti orang kedua yang mengacu pada orang yang diajak berbicara dan kata ganti orang ketiga yang mengacu pada orang yang dibicarakan. Untuk lebih jelasnya, dapat dilihat dari tabel berikut:

\begin{tabular}{llc}
\hline Kata ganti orang & tunggal & jamak \\
\hline Pertama & Saya, aku & Kami, kita \\
Kedua & Kamu, engkau, kau, anda & kalian \\
ketiga & Dia, beliau & mereka \\
\hline & http://donididon88.blogspot.com/2012/03/kata-ganti-orang-pronomina.html
\end{tabular}

http://donididon88.blogspot.com/2012/03/kata-ganti-orang-pronomina.html

Di dalam Bahasa Jepang, Pronomina Persona disebut Ninshoo Daimeshi. Penggunaan ini biasanya digunakan pada fungsi atau penggunaan masing-masing orang baik dengan orang $80 \mid \mathrm{P}$ a g e 
terdekat kita,tertua atau atasan-bawahan dan sebagainya. Menurut lori, Et, Al (2001) dapat dikelompokkan menjadi 3 bagian yakni

1. Jishoo/Daiichi Ninshoo Meishi yakni mengacu kata ganti orang pertama.

Contoh : watashi,watashikushi,atashi,boku,ore

2. Taishoo/Daini Ninshoo Meishi yakni mengacu kata ganti orang kedua.

Contoh : anata,kimi,omae,temee

3. Tashoo yakni mengacu pada orang yang menjadi pokok pembicaraan alias kata ganti orang ketiga.

Contoh : Kanojyo tachi,karera,soitsu,koitsu

\section{Faktor Penggunaan Bahasa Santun}

Pemilihan pronomina persona dalam suatu ujaran dipengaruhi oleh beberapa faktor yang berkaitan dengan kesantunan seseorang dalam berbahasa. Osamu Mizutani (1987: 3-14) dalam Kusumastuti (2008) memaparkan faktor-faktor yang mempengaruhi seseorang untuk menggunakan bahasa yang santun sebagai berikut

\section{1) Keakraban}

Bentuk sopan biasanya digunakan seseorang pada saat berbicara kepada orang asing (orang yang belum ia kenal) atau ketika baru bertemu seseorang untuk yang pertama kali. Bentuk sopan juga biasa digunakan pada saat memperkenalkan diri atau ketika berbicara di hadapan publik, seperti para penyiar di radio atau televisi.

2) Usia

Pada umumnya, orang yang lebih tua akan berbicara penuh keakraban terhadap orang yang lebih muda, sebaliknya orang yang lebih muda akan berbicara dengan lebih santun kepada orang yang lebih tua. Sementara itu mereka yang sebaya umumnya berbincang-bincang dengan lebih akrab kepada sesama.

3) Hubungan Sosial

Hubungan sosial di sini maksudnya adalah hubungan antara atasan dan bawahan dalam pekerjaan, hubungan antara penjual dan pembeli, dan hubungan antara guru dan murid. Hubungan ini juga disebut dengan istilah "hubungan profesional”. Dalam percakapan, mereka yang berstatus lebih tinggi, seperti para atasan, pembeli dan guru, bebas memilih untuk 
mengunakan bentuk netral atau bentuk sopan, sementara mereka yang berstatus lebih rendah tetap menggunakan bentuk sopan.

\section{4) Status Sosial}

Pada masa sebelum Perang Dunia II, orang - orang yang memiliki kedudukan sosial tertentu di Jepang, seperti keluarga kekaisaran dan para bangsawan, akan disebut dan dibicarakan dengan suatu istilah istimewa yang santun.

5) Jenis Kelamin

Percakapan cenderung menjadi lebih akrab di antara orang-orang yang berjenis kelamin sama daripada percakapan antara perempuan dan laki-laki. Namun, saat ini perbedaan penggunaan bahasa berdasarkan jenis kelamin sudah semakin mengecil. Beberapa ekspresi yang sangat feminin bahkan telah menghilang semenjak Perang Dunia II. Di saat yang bersamaan, bahasa laki-laki semakin diperbaharui agar mendekati bahasa perempuan. Sekarang telah menjadi hal yang umum jika laki-laki menambahkan "o" sebagai bentuk hormat pada kata cha, bento, kane, sake, atau kashi.

\section{6) Keanggotaan Kelompok}

Masyarakat Jepang membagi diri mereka melalui keanggotaan di dalam atau di luar grup, yang biasa dikenal dengan istilah uchi (内) dan soto (外). Oleh karena itu, orang Jepang menggunakan ekspresi dan bentuk bahasa hormat yang berbeda tergantung dari mitra tutur yang dihadapinya, apakah dia uchi (内) dan soto (外). Perbedaan ini didasarkan pada pemikiran bahwa seseorang harus mengidentifikasikan dirinya sendiri dengan keluarganya. Maka ketika seseorang berbicara kepada orang lain (soto) mengenai keluarganya (uchi), ia membicarakan mereka dengan cara yang sama seperti ketika ia membicarakan dirinya sendiri. Tidak digunakan bentuk sopan saat membicarakan keluarganya karena akan terdengar aneh jika berbicara mengenai diri sendiri dengan bahasa santun. Perbedaan bahasa yang digunakan

untuk uchi (内) dan soto (外) tidak sebatas pada lingkup keluarga saja, melainkan ikut meluas sampai pada organisasi atau perusahaan tempat ia bekerja.

7) Situasi 
Orang-orang akan memperhatikan tingkat kesantunan bahasa melalu situasi, bahkan ketika mitra tuturnya adalah orang yang sama. Misalnya, ada dua orang yang bertengkar, maka mereka akan mengganti tingkatan kesantunan bahasa yang mereka gunakan. Ada dua tipe perubahan, pertama dari bentuk sopan ke akrab dan yang kedua dari bentuk akrab ke bentuk sopan. Dalam pertengkaran, orang dengan tipe pertama akan memaki mitra tutur dengan sebutan yang buruk dan menggunakan bahasa yang kasar, sedangkan pembicara dengan tipe perubahan kedua akan menggunakan bahasa santun.

\section{Konsep Uchi-Soto}

Masyarakat Jepang pada umumnya mengenal konsep uchi-soto baik dalam lingkungan mereka baik dalam maupun luar. Uchi (内 ) adalah suatu istilah menunjuk pada lingkungan kelompok seseorang itu sendiri contoh keluarga atau orang-orang yang dianggap sudah menjadi anggota keluarga sendiri baik dari lingkungan kerja atau lingkungan sekolah. Sedangkan Soto (外) adalah suatu istilah yang berbalik dari uchi, berfokus pada lingkungan luar kelompok.

Meskipun pembagian seperti ini bisa dilihat di belahan dunia yang lain, tetapi konsep ini fundamental dan menyebar di seluruh Jepang, selain itu juga mempunyai pengaruh yang hebat di masyarakat Jepang, terutama dalam konteks hubungan sesama manusia. Dalam konteks hubungan sesama manusia, sangatlah penting untuk dapat berinteraksi dengan orang lain, baik dari kebudayaan yang sama maupun yang berbeda. Menurut Kimbal Young dan Raymound (dalam Soekanto, 1990: 61-62) interaksi sosial adalah kunci dari semua kehidupan sosial, oleh karena itu tanpa interaksi sosial, tak akan mungkin ada kehidupan bersama. Interaksi sosial dapat berupa orang-perorangan, antara kelompok-kelompok, maupun antara perorangan dan kelompok.

Nakane Chie (1970 dalam buku "Masyarakat Jepang") juga mengemukakan bahwa penentuan posisi dan status individu Jepang dalam masyarakat secara vertikal dipengaruhi oleh dua hal berikut: Attribute (shikaku) dan Frame (ba). Perbedaan attribute pada setiap individu Jepang dipengaruhi oleh: jenis kelamin, garis keturunan dan usia. Sedangkan frame lebih ditentukan pada lokasi terjadinya aktivitas ekonomi dan sejauh mana individu Jepang berperan dalam satu grup melalui satu kerangka kerja tanpa adanya pengaruh dari perbedaan attribute. 
Konsep uchi soto ini sudah diterapkan pada kehidupan sehari-hari termasuk dalam berbicara. Jika berbicara dengan orang di luar kelompoknya atau soto no hito maka orang Jepang cenderung meninggikan orang yang menjadi lawan bicaranya dengan menggunakan bahasa sopan/formal. Hirabayashi dan Hama (1992:3) menjelaskan tentang penggunaan bahasa Jepang yang berhubungan dengan uchi soto sebagai berikut

「内」人の間（家族、自分の会社人、自分のするグループの人など）が、 「外」人の間（新しくない人、他人、他会社の人、他のグループの人など）之話 し合ったり、その人たちを話題にする時、自分も含む「内」の人間に対しては謙 譲語、「外」の人間に対しては尊敬語を使う。 Ketika berbicara dengan orang dalam (keluarga, orang perusahaan yang sama, orangorang dekat di dalam kelompok kita) dan orang luar (orang tidak dekat, orang lain, orang di perusahaan lain, orang yang berada diluar kelompok kita), untuk menjadikan pokok pembicaraan, kita harus menggunakan kenjogo (bahasa perendahan) ketika membicarakan orang dalam, dan sonkeigo (bahasa hormat) ketika membicarakan orang luar.

Oleh sebab itu, masyarakat Jepang jarang menggunakan bahasa percakapan informal jika berbicara dengan orang yang baru dikenal karena akan terkesan tidak sopan.

\subsection{Metode Penelitian}

Sumber data dan data penelitan

Sumber data diambil dari komik One Piece volume 17, penulis memilih komik tersebut karena ditemukannya percakapan dengan tokoh utama/tokoh lain terhadap orang di sekitarnya memakai kata Omae.

Data dalam penelitian ini berupa percakapan yang menggunakan pemakaian kata omae yang ada di komik. Data terkumpul secara keseluruhan berjumlah 37 kata omae dalam sub percakapan di setiap chapter, dalam 37 kata omae dalam sub percakapan itu dibagi menjadi 2 kelompok uchi-soto dan terdapat kalimat yang mengandung formal/nonformal.

\section{Teknik pengumpulan data dan Teknik analisis}

Metode yang digunakan untuk pengumpulan data adalah metode studi pustaka yaitu dengan mencari percakapan kalimat dari komik One Piece volume 17 yang diikuti kata Omae. Langkah penulis lakukan dalam mengumpulkan data adalah 
1) Membaca per sub bab dari cerita dalam komik.

2) Mencari lalu menulis kalimat percakapan yang keluar dengan diikuti kata Omae dalam per subbab cerita.

3) Membuat daftar kalimat percakapan berupa kartu data dari 1 bab cerita ke bab cerita yang lain.

4) Mengidentifikasi dan menganalisa setiap kalimat percakapan yang diikuti oleh kata Omae.

5) Membagi analisis setiap percakapan dengan membagi jadi 2 kelompok yakni kelompok uchi-soto. Di dalam kelompok tersebut, ada pembagian berdasarkan situasi yakni formal dan nonformal.

Sedangkan untuk teknik analisis penulis menggunakan konsep uchi-soto menurut Nakane Chie dan Hirabayashi-Hama serta faktor-faktor penggunaan bahasa santun. Setelah itu mencatat percakapan yang memfokuskan pada pemakaian kata omae yang diujarkan pada para tokoh di komik One Piece dan menganalisis satu persatu percakapan di setiap sub bab cerita di komik One Piece.

\section{Teori yang digunakan}

Teori yang digunakan pada penelitian ini adalah teori konsep uchi-soto dari sudut pandang Nakane Chie dan Hirabayashi-Hama tentang penggunaan persona pronomina orang kedua dalam konsep uchi-soto.

\section{Hasil dan Pembahasan}

Dalam pembahasan ini, penulis akan menganalisis pemakaian omae dalam komik One Piece volume 17. Di sini, penggunaan kata omae dibagi dalam 2 kelompok yakni dalam kelompok uchi dan soto lalu dalam dua kelompok itu masing-masing berdasarkan penggunaan kata tersebut dalam situasi percakapan yang formal dan nonformal.

\subsection{Penggunaan kata omae dalam kelompok uchi}

a. Dalam situasi formal 


\begin{abstract}
せんいんナミ：ドクタリーヌ? ウチの船員の治療代なんだけどタダに！！そ れと私を今すぐ退院させてくれない?

Dokuta riinu ? uchi no senin no chiryou dai nandakedo tada ni ! sore to watashi wo ima sugu taiin sasetekurenai ?

Dr. Rin? Apakah ada biaya pengobatan termasuk untuk perbaikan kapal !! Selain itu apakah hari ini segera juga aku keluar dari rumah sakit?

ドクタリーヌ:

そりや無理な頼みだとわかっていってみただけかい治療代は おまえたちの船の積荷とあり金全部。お前(1) はあと2にちあんせい日ここで安静にしててもらうよ。。 sorya murina nano midato wakatteitte mitadake kaichiryou dai ha omae tachi no fune no tsumi ni to ari gane zenbu. Omae ha ato ni nichi koko de ansei ni site temurauyo..

Kalau itu permintaan yang tidak memungkinkan hanya mencoba mencari tahu biaya pengobatan yang harus dibayar dalam satu kargo oleh kalian semua. Kamu sebaiknya beristirahat di sini selama 2 hari..
\end{abstract}

\title{
Analisis :
}

Nami menanyakan kepada Dr.Rin bahwa adakah biaya pengobatan untuk dirinya termasuk juga perbaikan kapal serta apakah Nami sudah bisa sehat karena mengingat Nami dan lainnya harus melanjutkan perjalanan menuju Arabasta. Dr.Rin menjawab bahwa permintaan itu tidak dimungkinkan karena kapal Nami dan yang lainnya masih diperbaiki sehingga Dr.Rin menyarankan agar Nami sebaiknya beristirahat selama 2 hari. Tingkat keakraban dalam dua tokoh yang sedang berbicara adalah tidak terlihat karena baru saling mengenal satu sama lain saat bertemu di mana Nami sedang tergolek pingsan karena demam. Situasi adalah formal, omae (1) di sini Nami menanyakan kepada Dr.Rin bahwa apakah ada biaya pengobatan sekaligus perbaikan kapal serta apakah Nami bisa sehat karena harus melanjutkan perjalanan ke Arabasta. Hubungan sosial adalah hanya dokter dan pasien, Dr. Rin dan Nami berjenis kelamin sama yakni perempuan, status sosial Dr.Rin memiliki kedudukan lebih tinggi daripada Nami dan dilihat dari segi usia adalah Dr.Rin lebih tua dari Nami. Pemakaian kata omae (1) dipakai oleh Dr.Rin kepada Nami, walaupun Nami bertanya dengan tutur bahasa jishookei yakni istilah tutur bahasa yang mengakrabkan dan tidak menjaga jarak lalu dijawab oleh Dr.Rin dengan nada menyarankan dengan memakai kata omae (1) yang terbukti dalam kalimat jawaban "Omae ha ato ni nichi koko de ansei ni site temurauyo.." agar 
bisa beristirahat selama 2 hari. Dalam data percakapan 1, Nami termasuk dalam kategori uchi di dalam kelompok Dr.Rin karena Nami menggunakan tuturan jishookei untuk mengakrabkan dan tidak memberi jarak dengan Dr.Rin walaupun pertama kali kenal dan hanya sebatas dokter dan pasien.

\section{Temuan :}

Kata omae (1) yang dipakai oleh Dr.Rin untuk menjawab pertanyaan di mana Nami menanyakan secara formal dengan memakai tutur bahasa jishookei (istilah tutur bahasa yang mengakrabkan dan tidak menjaga jarak) kepada Dr.Rin bahwa apakah ada biaya pengobatan sekaligus perbaikan kapal serta apakah Nami bisa sehat karena harus melanjutkan perjalanan. Nami termasuk dalam kategori uchi penutur (Dr.Rin), karena Nami memakai tutur bahasa jishookei dengan Dr.Rin walaupun pertama kali kenal dan hanya sebatas dokter dan pasien serta status sosial Dr.Rin lebih tinggi daripada Nami . Pemakaian omae (1) adalah digunakan sesama jenis perempuan.

b. Dalam situasi non-formal

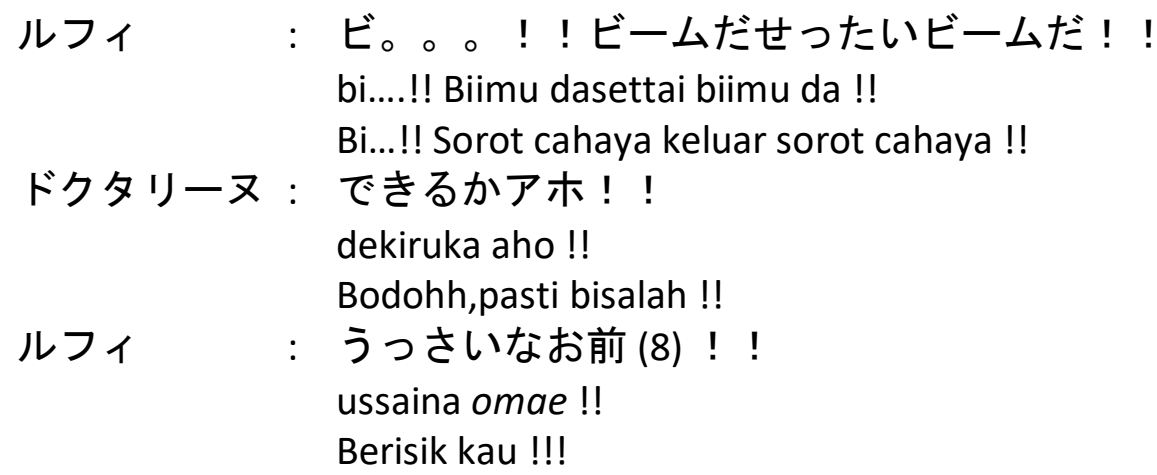

Analisis :

Luffy'pun melihat Chopper bertarunng melawan Chess Marimo dan takjub dengan kemampuan Chopper yang bisa menghabisi lawannya dalam waktu 3 menit bagaikan sorot cahaya yang keluar secara cepat namun Dr.Rin menganggap Luffy bodoh dan tidak tahu apaapa dengan kemampuan Chopper bisa bagaikan sorot cahaya lalu Luffy'pun memarahi dan membantah Dr.Rin cerewet dan merasa sok tahu. Tingkat keakraban adalah rekan walaupun dari kelompok bajak laut yang berbeda. Kata omae (8) yang digunakan oleh Luffy kepada Dr.Rin di dalam kalimat "ussaina omae !!" yang diartikan yakni "Berisik kau !!!" dengan nada marah 
kepada Dr.Rin. Hubungan sosial pada percakapan di atas adalah teman walaupun dari kelompok bajak laut yang berbeda, status sosial adalah mitra tutur mempunyai kedudukan tinggi daripada penutur, segi usia dilihat penutur lebih muda dari mitra tutur, dilihat dari jenis kelamin yakni berlawan jenis, Dr. Rin perempuan dan Luffy laki-laki. Situasi dalam percakapan di atas adalah nonformal, penutur takjub dengan kekuatan ranpall ball selama 3 menit bagaikan sorot cahaya namun mitra tutur menghina penutur bodoh lalu penutur marah. Mitra tutur termasuk dalam kategori uchi didalam kelompok penutur karena mitra tutur adalah teman walaupun dari kelompok bajak laut yang berbeda yang sama-sama akan melawan Whappol dan Chess Marimo.

Temuan :

Kata omae (8) digunakan pada situasi nonformal, Luffy'pun melihat takjub kemampuan Chopper bertarung melawan Chess Marimo dalam waktu 3 menit bagaikan sorot cahaya yang keluar secara cepat namun Dr.Rin menganggap Luffy bodoh dan tidak tahu apa-apa dengan kemampuan Chopper bisa bagaikan sorot cahaya lalu Luffy'pun memarahi Dr.Rin. Pemakaian kata omae (8) yang dipakai Luffy dan ditujukkan kepada Dr.Rin dengan nada marah dan dipakai kepada lawan jenis. Hubungan sosial pada percakapan di atas adalah teman walaupun dari kelompok bajak laut yang berbeda dan status sosial adalah mitra tutur mempunyai kedudukan tinggi daripada penutur. Mitra tutur, Dr.Rin masuk dalam kategori uchi di dalam kelompok penutur karena mitra tutur adalah teman penutur walaupun dari kelompok bajak laut yang berbeda.

2. Penggunaan kata omae dalam kelompok soto

a. Dalam situasi formal

エース ：もしコイツがここへきたらおれは10日間だけアラバスタでお前

(1)をまつとつたえてくれ。。

moshi koitsu ga koko hekitara ore ha jyuunichikan dake arabasuta de omae wo matsu totsutaetekure..

Jika ia datang kesini,aku sedang di Arabasta selama 12 hari dan kamu harus menunggunya datang.

男人 ：おいちょっと待ってくれ、あんたは名前は？？

oi chotto mattekure, anta ha namae ha ??

Oi tunggu sebentar,siapa namamu? 
Analisis :

Seorang dari pasukan Dolton menceritakan sekitar beberapa minggu lalu ada yang sedang mencari Luffy di kota. Pria muda itu menitipkan pesan bahwa jika Luffy datang dan memberitahu bahwa Ace di Arabasta selama 12 hari dan menyuruh pasukan Dolton untuk menunggu Luffy datang dan memberitahukan.

Tingkat keakraban adalah tidak terlihat karena sama-sama tidak mengenali satu sama lain. Pemakaian kata omae pada kalimat "moshi koitsu ga koko hekitara ore ha jyuunichikan dake arabasuta de omae wo matsu totsutaetekure.." dengan nada perintah secara formal yang dipakai oleh Ace kepada salah satu pasukan Dolton agar menyuruh pasukan Dolton untuk menunggu Luffy dan memberitahukan tentang Ace katakan. Hubungan sosial dalam percakapan adalah tidak saling mengenal, status sosial adalah Ace mempunyai kedudukan tinggi daripada pasukan Dolton, dilihat dari jenis kelamin adalah sesama jenis laki-laki dan segi usia kalau dilihat dalam percakapan ini adalah penutur (Ace) lebih tua daripada mitra tutur (seorang pria dari pasukan Dolton). Mitra tutur yang ditunjuk dalam kata omae disini masuk kategori soto di luar kelompok penutur karena tidak saling mengenal. Situasi formal di mana Ace sedang memberi pesan kepada beberapa orang dari pasukan Dolton agar memberitahukan Luffy kalau Ace sedang menunggu di Arabasta selama 12 hari.

Temuan :

Kata omae (1) dipakai saat situasi nonformal, Ace sedang memberi pesan kepada beberapa orang dari pasukan Dolton agar memberitahukan Luffy kalau Ace sedang menunggu di Arabasta selama 12 hari. Mitra tutur di sini masuk kategori soto di luar kelompok penutur karena tidak saling mengenal dan tidak akrab. Hubungan sosial dalam percakapan adalah tidak saling mengenal status sosial adalah Ace mempunyai kedudukan tinggi daripada pasukan Dolton. Pemakaian omae (1) digunakan oleh sesama jenis laki-laki.

b. Dalam situasi non-formal

こうりょくチョッパー: ランプルボールの効 カは３分！！３分でお前 (7) をたおす！！ ranpuru booru no kouryoku ha sanbun !! sanbun de omae wo taosu !!

Kekuatan Ranpoll ball adalah 3 menit !! Dalam 3 menit kamu akan kuhabisi !!

チェスマリモ：３分ムハハハハ！！3分どころかきさまごときかおれにかてるか！！ san bun muhahahaha!! Sanbun dokoro kakisama goto kika ore ni kateruka !! 
3 menit hahahaha !!! Apakah kamu bisa mengalahkanku dalam 3 menit ?!!

Analisis :

Tonny Chopper sedang melakukan persiapan untuk menyerang Chess Marimo dengan kekuatan permen bola khusus untuk melawan Chess Marimo tetapi Chess Marimo menganggap remeh pernyataan Tonny Chopper yang akan menyerang mereka dengan kekuatan Ranpoll ball selama 3 menit. Situasi pada percakapan tersebut adalah nonformal, Chopper akan bertarung melawan Chess Marimo dengan kemampuan ranpoll ball. Hubungan sosial antara penutur dengan mitra tutur adalah musuh,status sosial adalah Chess Marimo lebih tinggi dari Chopper, dilihat dari segi jenis kelamin adalah sesama jenis laki-laki dan segi usia adalah mitra tutur lebih tua dari penutur. Di dalam percakapan, penulis mendapat mitra tutur masuk dalam kategori soto di luar kelompok penutur karena dibuktikan pada kalimat "ranpuru booru no kouryoku ha sanbun !! sanbun de omae wo taosu !!" dimana penutur,Chopper bersiap-siap akan melawan musuhnya sekaligus mitra tutur,Chess Marimo.

Temuan :

Kata omae (7) disini digunakan saat situasi nonformal yakni Chopper akan bersiap- siap bertarung melawan Chess Marimo dan mengeluarkan kemampuan ranpoll ball untuk menghabisi Chess Marimo dalam waktu 3 menit di dalam kalimat "sanbun de omae wo taosu !!" . Di dalam percakapan ini, penulis mendapat mitra tutur masuk dalam kategori soto di luar kelompok penutur karena hubungan penutur dan mitra tutur adalah musuh dan status sosial adalah Chess Marimo lebih tinggi dari Chopper. Pemakaian omae (7) digunakan oleh sesama jenis laki-laki.

\section{Simpulan}

Dalam pembahasan yang telah disampaikan pada bab sebelumnya, maka penulis mendapat kesimpulan sebagai berikut.

Dari keseluruhan pemakaian omae dalam komik One Piece Volume 17 dikelompokkan lewat konsep uchi-soto masing-masing ada kelompok formal dan informal, omae digunakan pada scene yakni pertarungan, memarahi, mengejek/menyindir, senang, kaget, heran, bertanya-jawab dan menasehati kepada mitra tutur yang dekat dengan penutur atau mitra tutur yang tak dikenal dan dianggap musuh dari kelompok penutur. Dari keseluruhan 
percakapan di setiap kelompok uchi- soto formal dan informal yang mengandung kata omae, tidak hanya digunakan oleh sesama jenis laki-laki tetapi bisa digunakan oleh perempuan yakni yang sudah dekat dengan lawan bicara mereka baik sesama jenis maupun lawan jenis.

Penulis juga mengemukakan adanya percakapan dengan kata omae yang digunakan oleh penutur yang pertama kali kenal sebelum pertarungan sebelumnya dimulai dengan memberitahu secara formal dan halus kepada mitra tutur. Dalam percakapan tersebut, mitra tutur termasuk konsep soto (out group) karena orang tidak dikenal dalam kelompok penutur dan penutur menggunakan bahasa halus kepada orang yang pertama kali ia kenal.

\section{Referensi}

Chaer, Abdul dan Leonie Agustina. (2004). Sosiolinguistik: Perkenalan awal. Jakarta: Rineka Cipta.

Davies, Roger J dan Osamu Ikeno. (2002). The Japanese Mind. Boston: Tuttle Publishing Edizal. 2013. Kamus Jepang-Indonesia. Padang : Penerbit Kayupasak.

Drohan, Francis G. (1992). A Handbook Japanese Usage. Australia : Turtle Pub http://dictionary.goo.ne.jp/

http://donididon88.blogspot.com/2012/03/kata-ganti-orang-pronomina.html

Hirabayashi, Yoshisuke. Hama, Yumiko. 1988. Japanese For Foreigners: Honorifics. Tokyo: Kabushiki Kaisha.

Iori, Isao. Takanashi, Shino. Nakanishi, Kumiko. Yamada, Toshihiro. (2000). Nihon Bunpou Handobukku. Japan: 3A Corporation.

Indriani, Irine. (2011). Penggunaan Pronomina Persona Kedua Tunggal dalam komik GTO (Great Teacher Onizuka) 1 karya Fujisawa Tooru. Skripsi. Semarang: Universitas Dian Nuswantoro.

Izarina, Nindiya Ayu. (2012). Konsep uchi-soto dalam interaksi sosial orang Jepang di Surabaya: studi kasus pada orang Jepang yang bekerja di Universitas Airlangga. Japanology, Vol. 1, Surabaya : Universitas Airlangga.

Kenji, Matsuura. (1994). Kamus Bahasa Jepang-Indonesia. Kyoto: Kyoto Sangyo University Press. Kikou Nomoto. (1988). Kamus Pemakaian Bahasa Jepang Dasar Edisi Bahasa Indonesia Nababan, P.W.J. (1984). Sosiolinguistik Suatu Pengantar. Jakarta: PT. Gramedia.

Nakane Chie. (1970). Masyarakat Jepang. Jakarta: Sinar Harapan.

Oda Eiichiro. (2001). Shounen Jump. One Piece Volume 17. Jepang: Shueisha.

Rosita, Kusumastuti, Ajeng. (2008). Analisis Penggunaan Pronomina Persona Pertama dalam Cerpen Paruk Mura no Odoriko. Skripsi. Jakarta: Universitas Indonesia.

Saifudin, A. (2005). Faktor Sosial Budaya dan Kesopanan Orang Jepang dalam Pengungkapan Orei no kotoba. Laporan Penelitian Universitas Dian Nuswantoro.

Saifudin, A. (2006). Sapaan Untuk Orang Pertama dan Orang Kedua dalam Bahasa Jepang. Majalah IImiah Dian, Vol. 5 (3), 12-19. 
Saifudin, A. (2007). Ekspresi 'Diri' dalam Bahasa Jepang. Lite: Jurnal Bahasa, Sastra, Dan Budaya, 3 (1), 1-10.

Saifudin, A., Aryanto, B., Budi, IS. (2008). Analisis Fungsi Pragmatik Tindak Tutur Pertanyaan dalam Percakapan Bahasa Jepang antara Wisatawan Jepang dan Pemandu Wisata Indonesia di Candi Borobudur. Lite: Jurnal Bahasa, Sastra, Dan Budaya, 4 (1), 8-15.

Shanada Shinji. (1992). Kaisha Gengogaku. Tokyo. Oufuu.

Soerjono, Soekanto. (1990). Sosiologi Suatu Pengantar. Jakarta: PT. Rajawali. Sudjianto. 2001. Pengantar Linguistic Bahasa Jepang. Jakarta : Kesaint Blanc. Sutedi, Dedi. 2004. DasarDasar Linguistik Bahasa Jepang. Bandung : Humaniora. 